Tiwari, S., Pawar, G., Luttmann, E., Trujillo, R., and Sreekumar, A.(2018). "Visual Planning for Supply Chain Management of Prefabricated Components in Construction" In: Proc. $26^{\text {th }}$ Annual Conference of the International. Group for Lean Construction (IGLC), Chennai, India, pp. 1150-1159. DOI: doi.org/10.24928/2018/0419. Available at: www.iglc.net

\title{
VISUAL PLANNING FOR SUPPLY CHAIN MANAGEMENT OF PREFABRICATED COMPONENTS IN CONSTRUCTION
}

\author{
Saurabh Tiwari ${ }^{1}$, Girish Pawar $^{2}$, Eric Luttmann ${ }^{3}$, Rudy Trujillo ${ }^{4}$ \\ and Aiswarya Sreekumar
}

\begin{abstract}
One of the challenges in the supply chain management of prefabricated components is the communication gap between the jobsite and the fabrication shop to coordinate on the deliveries. The context is the supply chain of light gauge metal stud panels that are digitally fabricated using BIM and CNC Robots in the US construction industry. The solution implemented was a cloud-based ordering application. the superintendent in the field interface with the BIM of Metal Stud Panels on an iPad, sequences the panels in the order he/she wishes to install. The order placed by the superintendent is received by the fabrication shop, which then initiates the fabrication of the panel from the same BIM, in the same sequence using the CNC robots. Once fabricated, the panels are divided into batches and transported to the site for installation. This helps in prioritizing fabrication, assembly and shipping of panels as per the needs of various jobsites. The just-in-time fabrication and delivery enables lean workflow of construction material, and minimizes waste in over-production, transportation and inventory. The paper will focus on the process in detail and benefits from this approach.
\end{abstract}

\section{KEYWORDS}

flow, visual management, job sequencing, logistics, supply chain management.

\footnotetext{
Director, vConstruct Private Limited, Pune, India, +91- 8446001610, saurabht@ vconstruct.in Sr. Project Engineer, vConstruct Private Limited, Pune, India, +91- 9403976679, girishp@vconstruct.in

3 BIM Project Engineer, Digital Building Components, Phoenix, Arizona, +12159138611,ericlu@ digitalbuilding.com _ C

4 Design Manager, Digital Building Components, Phoenix, Arizona,+1- 6023294255, rudyt@digitalbuilding.com

5 Sr. Project Engineer, vConstruct Private Limited, Pune, India, +91- 8826367246, aiswaryas@vconstruct.in
} 


\section{INTRODUCTION}

Overall logistics management for engineer-to-order components is well managed by creating batches and defining sequence, the progress of fabrication and installation is tracked using tracking tools(Bataglin et al. 2017). The product centric approach defines the product life cycle. Activities from design phase, fabrication phase, assembly, shipping are tracked through the product(Dave et al. 2015). This paper focuses on sharing an insight into the issues in the current supply chain dynamics of prefabricated construction components (in this case, Light Gauge Metal Stud Panels) and an approach to solve those by the application of above mentioned principles.

In this case study, Building information model (BIM) enabled mobile application (iPad app)has been used as a primary mechanism for solving the issues. (Peñaloza et al. 2016) mention the guidelines such as aligning production and installation plans, achieving real-demand from site by using 4D BIM tools, helps in reducing the wait time for installation.

The issues addressed in this paper, in the context of supply chain dynamics, are demand variability, material re-handling, coordination challenges with other trades, inefficient planning and design change creep into the submittal/shop drawings and procurement phase thereby either reducing the lead time for fabrication or wastage.

Changes to the construction schedule area challenge for fabricators. It is important that the subcontractors and fabricators efficiently create and update the installation and fabrication plan throughout the process(Viana et al. 2015). This paper shares a methodology on how timely planning helps to achieve a better production control as production logistics is based on real time demand and feedback from site. The context of this paper is a factory of prefabricated metal stud panels that ships these components to construction projects. Installation of these prefabricated panels takes four times less time than manual installation. This paper presents the challenges that the factory is facing due to varying demand and communication inefficiencies from construction jobsites.

\section{DETAILS OFFACTORY}

The factory is operated by a specialty contractor and manufacturing firm that fabricate sand installs metal stud panels. The panels fabricated in the factory are assembled and transported to various project sites. The factory has a team that develops BIM for the projects. This BIM is also used in coordination with other building trades. Once the coordination is complete, the factory receives orders from the superintendent on the construction jobsite, which starts the fabrication process. The setup includes moulding sheet metal to form metal studs with proper sizes, cutting them in required length, punching holes, these operations are carried out by $\mathrm{CNC}$ machines. Robotic arms are used to weld the studs together to form a panel. Sheetrock is mounted on the panels once the fabrication is complete. All the panels are stacked at a storage yard, which is then transported to the sites as per the demand. All processes mentioned here is BIM enabled.

\section{EXISTING PRODUCTION PROCESS}

The superintendent on site is aware of site conditions and have in-depth idea of construction schedule for the project. In the existing process the factory receives installation sequence for the superintendent in the form of marked up PDFs. The usual 
practice is modellers in the factory email panel drawings to the superintendents on site and they finalize the installation sequence. Since there are different types of panels like the priority panels, load bearing, non-load bearing, leave-out panels, metal studs ceiling assemblies, joists, exterior panels etc., the sequence of installation changes as per the type of panels as well as the location of panels. Thus, these marked up drawings not only have sequence numbers assigned to the panel, but also distinct colours applied to the different panel types. Sequence numbers are marked on the pdf and emailed to the factory. These marked up drawings are the basis for fabricating the panels and other downstream supply chain activities.

\section{METHODOLOGY}

\section{BASIS OF SOFTWARE DEVELOPMENT}

Fabricators have been facing challenges like bulk ordering, multiple orders, less correspondence, miscommunication, schedule delays. The orders are placed in bulk which leads to higher inventory cost. The gap between site and subcontractor is a common problem in construction. Furthermore, miscommunication between site and fabricator results in overproduction, wastage of material, delay in delivering panels on site, logistics problem like re-handling and thereby, causing overall delay. The focus in developing this software application is to overcome/reduce these challenges and to have a smooth flow of information as well as lean flow of panels throughout the process from ordering to fabrication to installation. There are two factors considered while implementing requirements to the software. First is that the sequencing data input should be done directly from the authorized person on site and secondly, input it in a format such that it can be digitally used for fabrication and assembling purpose. Thus the proposed system supports process transparency through visual management by making it easy for all involved to see and order parts (panels), cycle time reduction due to the streamlined process, potential elimination or reduction of other types of waste such as rework, waiting, re-handling and excessive transportation(Koskela 1992). The focus is to streamline the overall process. The benefits over existing process using the app "Flow" is presented in the following sections.

\section{MORE TIME AVAILABLE FOR PLANNING}

Panel installation activities are typically on the critical path. Furthermore, design and coordination changes often take more time than planned, thereby shrinking the lead time of panel production at the factory. Within this reduced time period, the superintendent and the fabricator must finalize the sequence of installation before fabricating the panels. In the existing process, the fabricator provides panels drawings to the superintendent only once BIM coordination is signed-off. In the new process, the superintendent can start the panel sequence planning right after the design phase and has the entire coordination and submittal phase to finalize the planning for installation. The reason here being that existing sequencing process being $2 \mathrm{D}$ pdf based, is not agile enough to absorb change intensive coordination phase and thus this effort is preferred to be a onetime approach, ideally best done after the coordination phase. The new approach is BIM enabled with sequencing done real-time on the latest model (automatically fetched from A360 docs). 
Model changes are easily incorporated to the BIM enabled sequence planning process based on model version comparison. Figure 1 below represents additional time available for the superintendents to plan the work.

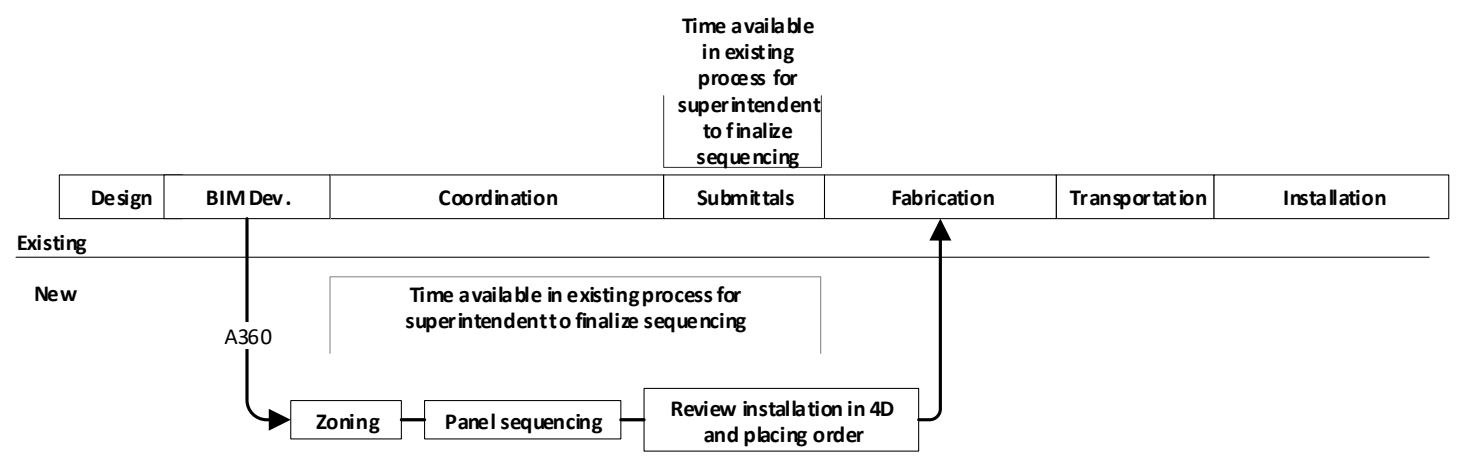

Figure 1: Comparison between Existing and New

\section{ABILITYFOR EVALUATING MULTIPLE SEQUENCING SCENARIOS}

The process of manually adding sequence numbers is tedious and time consuming. There is very little scope for iterations to these mark-ups in the short duration of time. The Figure 2 below shows manual sequencing of panels achieved using pdf-based application. The new application holds ability to maintain sequence data and BIM in a database. The usage of the BIM model within the app outperforms the current manual pdf-based approach due to the agility of the BIM model to run multiple sequencing scenarios, use of quantity information in the model to derive duration of installation and evaluation of each of the scenarios based on total installation duration. This ensures that the sequence planning is optimum and has been vetted out carefully. The workflow ensures use of the latest and greatest BIM as the iPad app fetches it from Autodesk 360 platform on a real time basis.

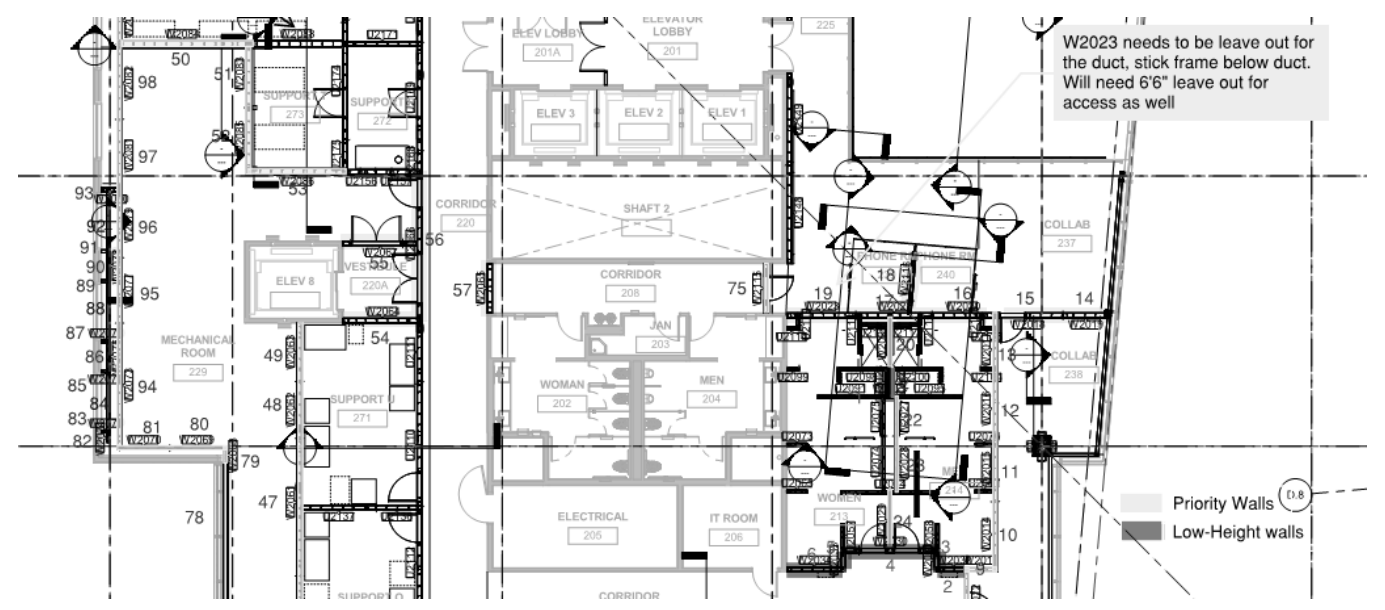

Figure 2: Manual sequencing done by Project Engineers using Bluebeam Revu 


\section{ABILITY TO PLAN SEQUENCING BY ZONES AND ACROSS FLOORS}

The existing 2D pdf-based process does not provide the capability to prioritize sequencing of panels between floors. The superintendent sequences panels on separate 2D panel install layout drawings in a disjoint manner. The new process using app 'Flow' has a location-based management system (LBMS) through which zones/areas/workface are defined to group and segregate panels. The size of these zones is defined based on the amount of work that can be done within a planning cycle under the last planner approach (typically a week).Figure 3 shows sequencing of zones between levels, thereby providing another dimension in sequence planning which was not available while it was being done using 2D pdf drawings. Panels in the building are divided in two major scopes based on the functionality as shown in Figure 3, interior panels and exterior panels. Interior partition panels and ceiling/floor panels are included in interior category, whereas exterior face panels are included in exterior category.



Figure 3: Floor Zone combination concept (Left) and Floor Zone combination in app (right)

\section{QUANTITATIVE INFORMATION}

2D drawings do not provide readily available quantitative information. It does not automatically tell the planner how long the sequenced panels will take to install. The 'Flow' automatically gives this information. The process is, once the areas are drawn on floor plan, user needs to select Floor and Zone (FZ) combination and apply install rate. Generally, installation rate is determined in linear feet (lf)/day/crew and the length of panel varies from 8 ' to $12^{\prime}$. Based on the available data on number of crew shifts and leveraging the quantity information in BIM (lf of panels), this install rate helps identify the quantum of work that can be put in place in one calendar day. As mentioned earlier, different types of panels (load bearing, non-load bearing etc.) are categorized under subscope. Install rate varies from one type of panel to other and it varies even by location. It also helps in validating the work area definition, if the number of panels within a work area can be installed within the planned duration or not. Color-coding of sequence numbers instantly notify number of days required for installation.User can sequence the panels for an area at any point of time.Figure 4 shows manual sequencing and sequencing using 'Flow' 


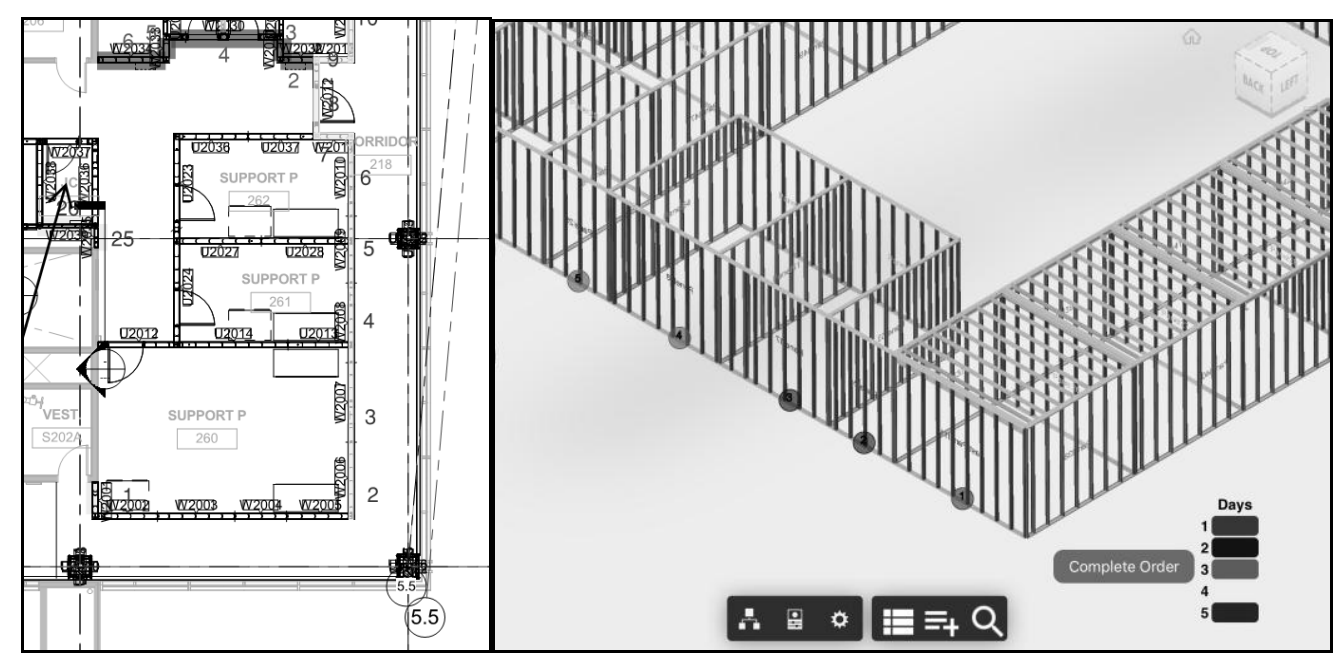

Figure 1: Manual sequencing (left) \& Panel sequencing using App (right)

\section{D REVIEW OF PANEL INSTALLATION}

Another challenge observed in the current process is effective coordination with other trades. Since the panels are prefabricated, they need to get installed prior to MEP installation. The factory has experienced challenges in the past, when MEP subcontractor installed utilities before the panels. This happened because factory did not receive any indication about the priority panels and leave-out panels from the project team. Lack of communication between the site and the factory has often led to delay in installation of panels, since either the MEP trade had to remove their parts while drywall team waited to install or MEP trades were not able to remove the runs and multiple panels needed to be modified or were not installed and those walls had to be manually installed.

Current application provides ability to specify and visualize priority panels and leave out panels. 4D visualization helps in understanding the overall installation of panels in context to other building trades. Though the current development does not show installation of other trades, in the ensuing version the user can manually export user data of zones, sequence numbers and start date of panel installation to master construction schedule and see the overall 4D.Plannerscan better visualize, accurately analyze, communicate and reduce possibility of coordination errors with other trades.

The superintendent reviews the order via 4D and places the orders. He/she reviews the system generated delivery date for the panels and can edit it if required. Once the order is confirmed, factory initiates fabrication process and once fabricated panels are shipped to arrive on site by the delivery dates as specified in the order. Figure 5 shows the order summary report. 


\begin{tabular}{|c|c|c|c|}
\hline \multicolumn{3}{|c|}{ Order Cart } & Place Order \\
\hline \multicolumn{4}{|c|}{$\Theta \quad$ Scope: Interior } \\
\hline \multicolumn{4}{|c|}{ - Subscope: Soffit Walls } \\
\hline & Floors \& Area Sequence & Start Date & Delivery Date \\
\hline $\boldsymbol{\otimes}$ & F1-A1 100\% panels sequenced & 01 January 2018 & 01 January 2018 \\
\hline $\boldsymbol{\otimes}$ & F1-A2 100\% panels sequenced & 01 January 2018 & 01 January 2018 \\
\hline $\boldsymbol{\otimes}$ & F1-A3 $0 \%$ panels sequenced & 01 January 2018 & 01 January 2018 \\
\hline $\boldsymbol{\otimes}$ & F1-A4 $0 \%$ panels sequenced & 01 January 2018 & 01 January 2018 \\
\hline \multicolumn{4}{|c|}{ - Subscope: Floor Panels } \\
\hline & Floors \& Area Sequence & Start Date & Delivery Date \\
\hline $\boldsymbol{\otimes}$ & 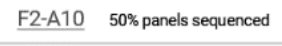 & 01 January 2018 & 01 January 2018 \\
\hline $\boldsymbol{\otimes}$ & $\underline{\mathrm{F} 2-\mathrm{A} 10} \quad 50 \%$ panels sequenced & 01 January 2018 & 01 January 2018 \\
\hline & & & Place Order \\
\hline
\end{tabular}

Figure 5: 'Place order' on app

\section{MINIMIZE MATERIAL RE-HANDLING}

Post-fabrication, panels are bundled, stored in factory, shipped, stored on site and installed. If panels are not fabricated as per the installation sequence it leads to the risk of material re-handling in each of the stages mentioned above.Improper placement of panels on loading yard and trucks affects their unloading on site. Because of this, site crew had to first rearrange the panels and then move them to the installation location. Also, there have been instances when schedule got delayed because the panel bundles received on site were not those expected by the project team. Proposed app provides sequencing data, which is used to create bundles, using which panels are stacked as per Last In First Out (LIFO) logic. The process of creating panel bundles is shown as in Figure 6.
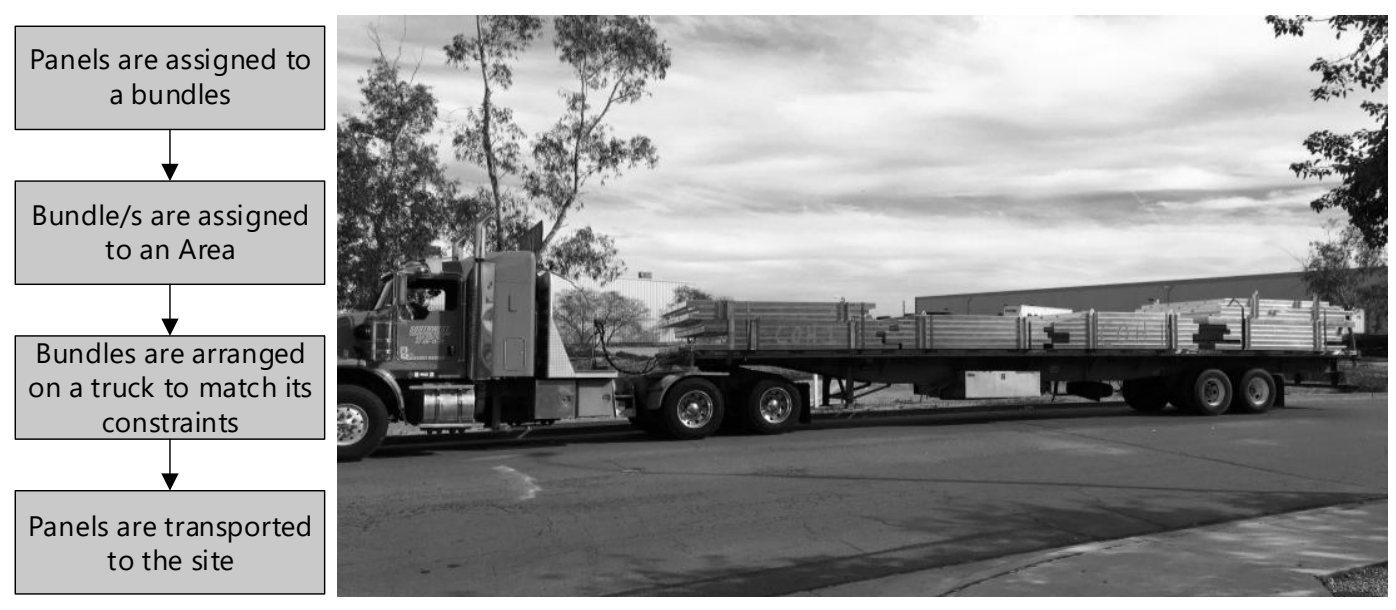


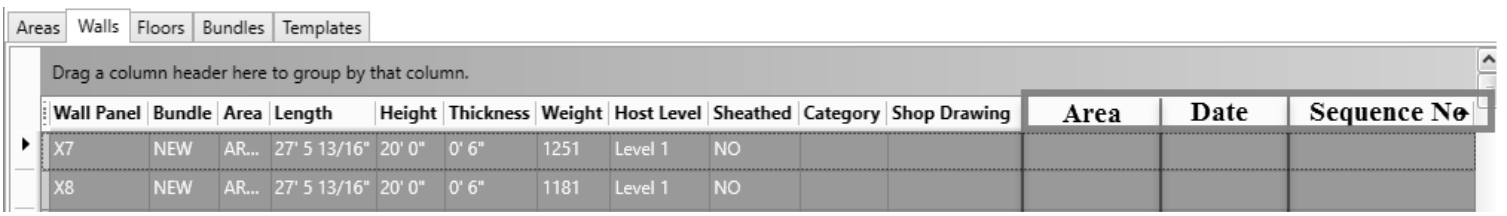

Figure 6: Process of panel bundling

\section{DEMAND VARIABILITYDUE TOMULTIPLE PROJECTS}

The current process provides sequencing data from multiple projects in a format (pdf) that does not support effective supply chain across those projects with the factory. The new process using the app 'Flow' proposes to enable efficient coordination of panel fabrication and shipping between projects. The app 'Flow' will provide order summary report and 4D output in a format that will enable assimilation from multiple projects to fabrication workflow. Figure 5 (Order Summary) and Figure 7 (4D time liner review) shows the input to the fabrication workflow.

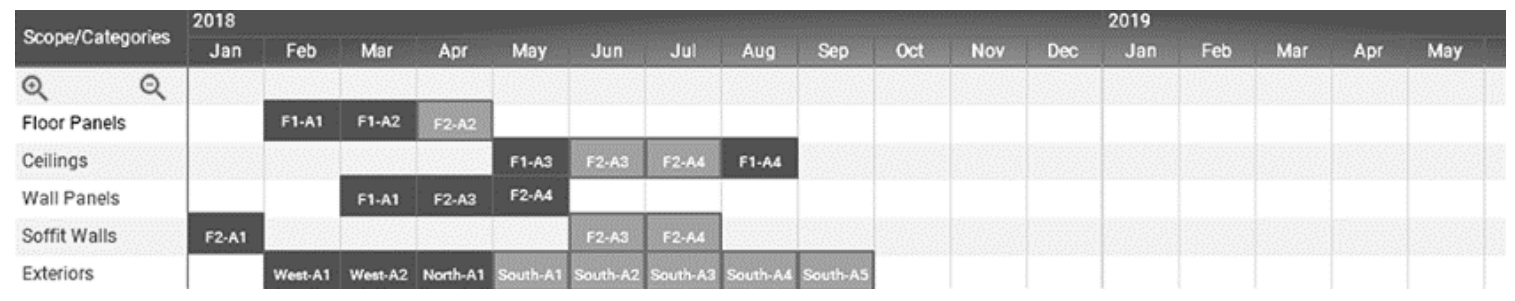

Figure $2: 4 \mathrm{D}$ timeliner

\section{CONCLUSION AND FUTURE SCOPE}

The future version of app 'Flow' will include functionalities for tracking status of material delivery (using IoT) and progress tracking of installation on site. It is also planned to include the other trade models to improve the overall installation sequence. The Application can further be extended in future versions to record and track other stakeholders' reviews/comments, design and constructability review features on a single platform. This paper explains qualitative comparison between existing and new process for managing the demand and supply of metal framed panels which is summarized in the following Table 1. Quantitative comparison between existing and proposed processes is yet to be measured as the app is in beta testing phase. 


\begin{tabular}{|c|c|c|}
\hline Construction process & Existing Process & New Process using App 'Flow' \\
\hline $\begin{array}{l}\text { Planning the installation } \\
\text { of building elements } \\
\text { and sequencing }\end{array}$ & $\begin{array}{l}\text { Sequence of installation is } \\
\text { defined by the } \\
\text { superintendent only when } \\
\text { all the submittals are ready. }\end{array}$ & $\begin{array}{l}\text { The process using the app gives the } \\
\text { project team the ability to plan the } \\
\text { installation sequence from design } \\
\text { phase. } \\
\text { The app user can define the categories } \\
\text { of panels, E.g. priority panels and } \\
\text { leave-out panels (Reduced cycle time } \\
\text { due to streamlined process) }\end{array}$ \\
\hline $\begin{array}{l}\text { Location based } \\
\text { planning }\end{array}$ & $\begin{array}{l}\text { The superintendent } \\
\text { provides markup of } \\
\text { installation plan on the } \\
\text { panel install layout } \\
\text { drawings. The process of } \\
\text { marking zones and } \\
\text { sequencing on } 2 \mathrm{~d} \text { sheet is } \\
\text { tedious and a cumbersome } \\
\text { process. Sequencing } \\
\text { across floor is not possible. }\end{array}$ & $\begin{array}{l}\text { Areas can be easily marked on } 2 d \\
\text { sheets. Panels can be added/removed } \\
\text { from a zone hence sequencing across } \\
\text { floor is made possible. (Reduces the } \\
\text { share of non-value adding activities) }\end{array}$ \\
\hline $\begin{array}{l}\text { Communication } \\
\text { between the } \\
\text { Superintendent and the } \\
\text { factory }\end{array}$ & $\begin{array}{l}\text { Information flow in this } \\
\text { process may lead to } \\
\text { misunderstanding and } \\
\text { waste due to rework }\end{array}$ & $\begin{array}{l}\text { Sequence report generated through the } \\
\text { "flow" application gives a clearer picture } \\
\text { of fabrication requirement. (Elimination } \\
\text { of waste such as rework, waiting, re- } \\
\text { handling and excessive transportation) }\end{array}$ \\
\hline Quantitative planning & $\begin{array}{l}\text { Existing process doesn't } \\
\text { give the idea of overall } \\
\text { production levels from } \\
\text { different projects }\end{array}$ & $\begin{array}{l}\text { Integration of BIM and IT will help to } \\
\text { understand the forecast. (Increased } \\
\text { process transparency through visual } \\
\text { management) }\end{array}$ \\
\hline Review of installation & $\begin{array}{l}\text { Review of orders cannot be } \\
\text { done. }\end{array}$ & $\begin{array}{l}\text { 4D of panel installation will be used as } \\
\text { a review by the superintendent } \\
\text { (Increased visualization of the process) }\end{array}$ \\
\hline
\end{tabular}

Table 1: Comparison between as-is and as-proposed process

There are some limitations and challenges to the app implementation. For the app to work properly the models and the sheets must be uploaded with predefined nomenclature. Framing elements should have scope and sub scope properties defined for the app to read and accurately pull them in respective categories. In the project setting a user at present cannot define holidays and the app uses a linear process for calculating the start dates of installation. Another limitation is that the app user cannot import construction master schedule and link the activities to the framing elements in the current app version. File types for models is limited to particular file formats such as .nwc, .rvt and .dwfx. The app is at present developed for $\mathrm{iOS}$ and not for other platforms like Android, Windows, etc.

The current version of this application mainly focuses on improving the existing production process. The application proposes to help the fabricator to streamline the process with clearer picture of production requirements. It will also consider the demand variability due to multiple projects in pipeline. The app proposes an effective integration and communication between projects and the factory. Fabricators using the app will 
better understand the installation of panels with respect to other trades, which will reduce the risk of rework on the field.

\section{ACKNOWLEDGEMENT}

Thanks to DPR Construction, being an advocate for prefabrication in construction. Thanks to Digital Building Components for identifying improvement opportunities in supply chain and swiftly trying to solve those by using technology.

\section{BIBLIOGRAPHY}

Bataglin, F. S., Viana, D. D., Formoso, C. T., and Bulhões, I. R. (2017). “Application of Bim for Supporting Decisionmaking Related to Logistics in Prefabricated Building Systems.” II(July), 71-78.

Dave, B., Kubler, S., Pikas, E., Holmström, J., Singh, V., Främling, K., Koskela, L., and Peltokorp, A. (2015). "Intelligent Products: Shifting the Production Control Logic in Construction (With Lean and BIM)." 23rd Annual Conference of the International Group for Lean Construction, 341-350.

Koskela, L. (1992). "Application of the new production philosophy to construction." Center for Integrated Facility Engineering, 1-81.

Peñaloza, G. A., Viana, D. D., Bataglin, F. S., Formoso, C. T., and Bulhões, I. R. (2016). "Guidelines for integrated production control in engineer-to-order prefabricated concrete building systems: Preliminary results." IGLC 2016 - 24th Annual Conference of the International Group for Lean Construction, 103-112.

Viana, D. D., Tillmann, P. A., Sargent, Z., Tommelein, I. D., and Formoso, C. T. (2015). "Analysis of HVAC Subcontractor Mechanisms for JIT Materials Supply to a Construction Site." 23rd Annual Conference of the International Group for Lean Construction, 246-255. 